\title{
Intramedullary Nailing of Type I and Type II Open Leg Fractures after 6 Hours at Yopougon Teaching Hospital
}

\author{
Traoré Alidou ${ }^{*}$, Mbende Alban Slim², Sery Bada Justin Léopold Niaoré1, \\ Mobiot-Aka Christelle1, Soumaro Kanaté Daouda1, Boka Eva Rebecca1, \\ Sie Essoh Jean Baptiste1, Bamba Insa1, Lambin Yves ${ }^{1}$

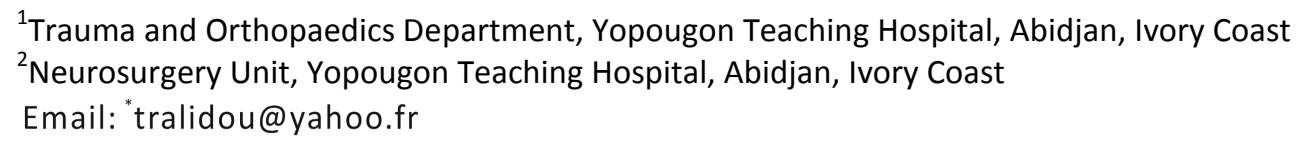

Received 17 May 2016; accepted 17 July 2016; published 20 July 2016

Copyright (C) 2016 by authors and Scientific Research Publishing Inc.

This work is licensed under the Creative Commons Attribution International License (CC BY). http://creativecommons.org/licenses/by/4.0/

(c) (i) Open Access

\section{Abstract}

Emergency debridement has long been the standard of care for open fractures of the tibia as infection is an important complication. In developing countries, patients are admitted to teaching hospitals 6 to 24 hours after their initial trauma. We sought to evaluate outcomes of nailing and correlations between the risk of infection and the delay in surgery. Materials and methods: Medical files of 48 men and 15 women with a combined total of 63 open fractures of the leg during a 12-year period were reviewed. The mean age was 29 years. Thirty-four type I and 29 type II open fractures according to the classification of Cauchoix and Duparc were treated with Küntscher nail after excision/debridement. Preoperative CRP was performed in 27 patients and in 22 cases it was positive. Twenty-six fractures were treated within a period of 6 to 24 hours, and a further 37 was operated on beyond 24 hours. The average waiting time before surgery was 2 days. Results: The infection was present in 11 patients $(17.5 \%)$. We failed to establish any correlation between the time of treatment and the occurrence of infection for both type I and type II fractures treated during the same intervals with $p=0.244(p>0.05)$. But we established a correlation between the type of open fracture and the occurrence of infection with $p=0.01(p<0.05)$. There were 10 cases of infection among 22 cases of positive preoperative CRP. We couldn't find a correlation between the positive value of the pre-operative CRP and the occurrence of infection. Seven cases of infection were treated with appropriate antibiotherapy and early revision surgery. Four others cases complicated to bone infection $(n=2)$ and septic nonunion $(n=2)$. The average time of hospitalization was 22 days. The average time for fracture healing was 7 months. Conclusion: The rule of six hours is hardly applicable in our contexts. Our study showed no correlation between the preoperative period and the occurrence of infection.

*Corresponding author. 


\section{Keywords}

\section{Intramedullary Nailing, Open Fracture, Leg, Six Hours}

\section{Introduction}

Infection constitutes the major complication of open fractures of the leg. Understanding or reducing its occurrence has been based over the last thirty years on four factors: the introduction of new materials for stabilization, the use of the external fixation, the development of soft tissue repair methods, a better understanding of the concept of strategy and a renewed approach to the surgical time of tissue excision. Early antibiotherapy must be part of the above [1]-[5].

Open tibia fractures are an orthopaedic emergency. Surgical intervention has traditionally been recommended within $6 \mathrm{~h}$ of injury to decrease the risk of infection. Debridement of the open wound within six hours after the injury is a widely accepted standard of care. The precise origins of the so-called "six-hour rule" are unclear. Some claim that it stems from an 1898 experiment during the Spanish-American war by German military surgeon Friedrich [6], in which guinea pigs with contaminated soft-tissue wounds had lower rates of infection when debridement was performed within six hours. Others however point to a 1973 study by Robson et al. [7]. In developing countries where road infrastructures are often degraded and medical facilities are inadequate, patients often reach teaching hospitals 6 hours or 24 hours after the initial trauma [8]-[10]. These hospitals face a shortage of implants such as external fixation. Despite late admission of most patients, we performed intramedullary nailing of type I and II open fractures according to Cauchoix and Duparc classification [11]. We sought to evaluate outcomes of nailing and correlations between the risk of infection and the timing of surgery.

\section{Material and Methods}

This was a retrospective study which spanned over a 12-year period (2000 to 2012). A total of 48 men and 15 women who were hospitalized with type I and II open fracture of the leg according to Cauchoix and Duparc classification were included. The average age was 29 years with a range of 15 to 52 years and the age group most affected was between 15 and 30 years. The study sample was composed of manual workers $(\mathrm{n}=36)$, office staff $(n=12)$, merchants $(n=6)$, drivers $(n=5)$ and unemployed $(n=4)$. The mechanism of injury was road traffic accident $(n=57)$, sport $(n=1)$, firearms $(=1)$ and other $(n=4)$. Thirty four patients presented with a type I open fracture and 29 cases developed a type II fracture. According to the AO classification [12], 33 fractures were type A, 22 cases type B and 8 fractures type C. Associated injuries were floating knee $(n=2)$ and the bilateral fractures $(n=6)$. All patients benefitted from Küntscher intramedullary nailing.

C-reactive protein (CRP) was tested preoperatively in 27 of 63 patients and was positive in 22 patients according to the standards of the laboratory which was over $6 \mathrm{mg} / \mathrm{l}$.

The time between the injury and the surgical incision for debridement was calculated from transfer and hospital records. All times were rounded to the nearest hour. Twenty-six patients were operated within 6 to 24 hours after the initial trauma and in 37 cases, surgery was performed beyond 24 hours. The average waiting time before surgery was 2 days (Table 1 ).

Surgical treatment consisted of debridement and stabilization by intramedullary nailing (Figure 1). Junior surgeons operated 25 patients and 38 patients were operated by the senior surgeon. Patients were referred to the kinesitherapy department to ensure mobility of the ankle and the knee. Early empiric antibiotherapy was given to all patients and was maintained until complete wound healing. It consisted of either a bi-antibiotherapy ( $3^{\text {rd }}$ generation cephalosporin and imidazole) or a tri-antibiotherapy ( $3^{\text {rd }}$ generation cephalosporins, aminoglycosides and imidazole).

We assessed the risk of infection and consolidation. Infection was assessed based on oozing from the wound associated with local signs of inflammation, spontaneous and deep wound dehiscence with a fever of more than $38^{\circ} \mathrm{C}$ or oozing of franc pus. Bone healing was assessed on clinical and radiographic grounds at regular monthly intervals until total consolidation. Clinically, the assessment of consolidation was based on the lack of pain and proper healing. Radiological criteria of consolidation were the presence of a bone callus and fracture healing on at least two radiographic views (Figure 2). 


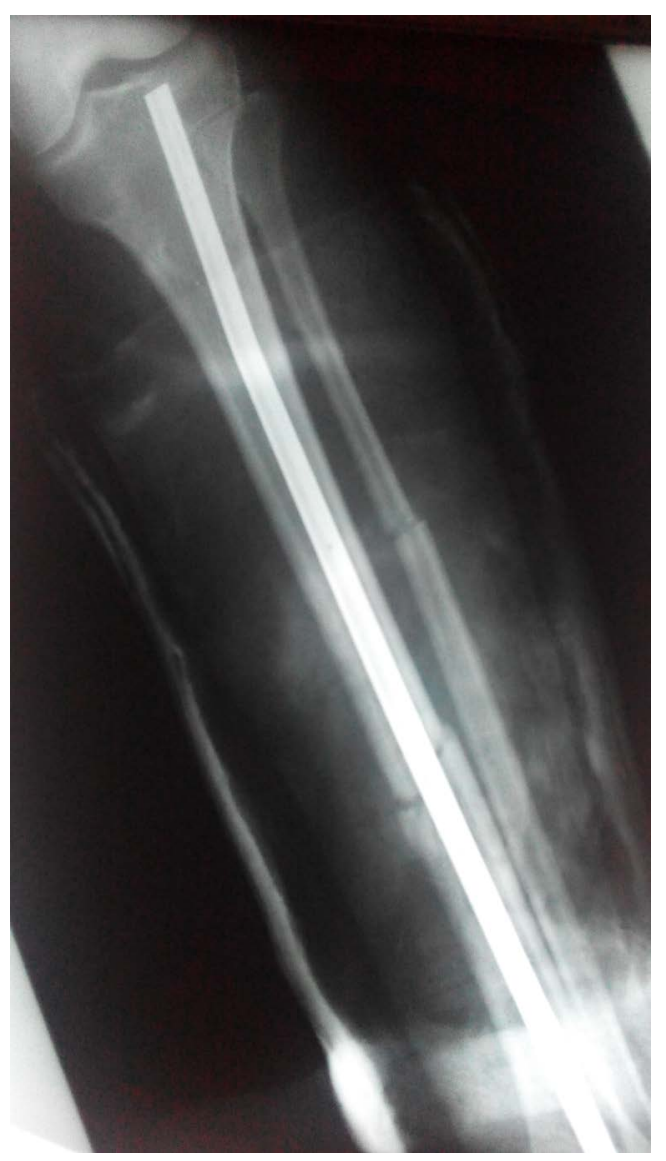

Figure 1. Initial surgery with a Küntscher nail.

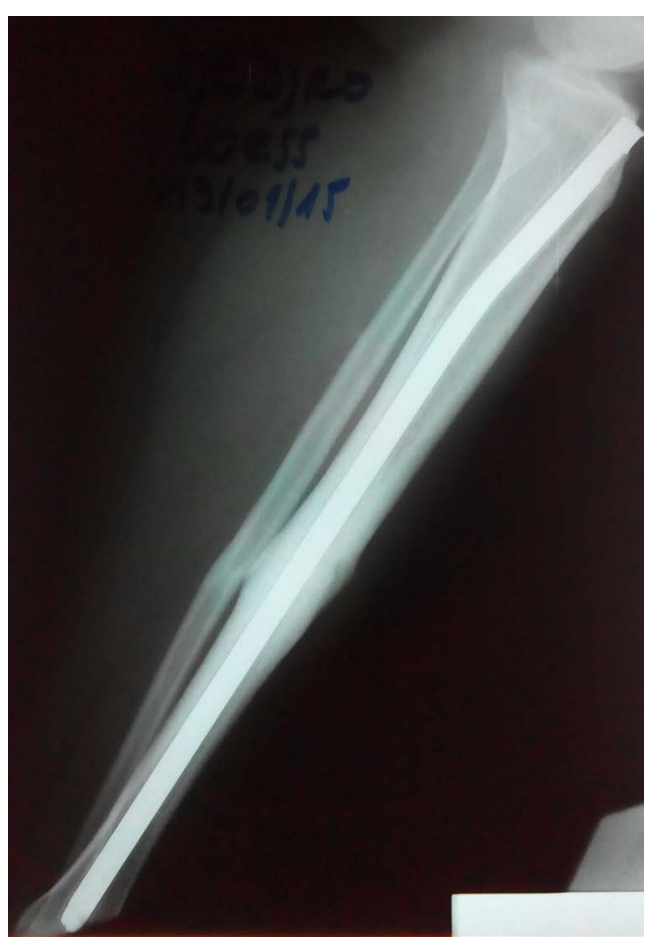

Figure 2. Control radiograph showing good consolidation. 
Table 1. Distribution of open fractures according to time to debridement and type of open wound.

\begin{tabular}{|ccc|}
\hline & \multicolumn{2}{c}{ Debridement and nailing } \\
\hline Cauchoix and Duparc classification & $\mathbf{6}-\mathbf{2 4} \mathbf{~ H}$ & $>\mathbf{2 4} \mathbf{~ H}$ \\
\hline Type I & 16 & 18 \\
Type II & 10 & 19 \\
Total & 26 & 37 \\
\hline
\end{tabular}

Statistical analyses were performed using the Chi Two test $(\mathrm{p}<0.05)$. The study was approved and validated by the local ethics committee.

\section{Results}

Eleven patients had infection which is an overall rate of $17 \%$ (Table 2). We failed to establish a relationship between the timing of treatment and the occurrence of infection for both type I and type II open fractures treated during the same time intervals, $p=0.244(>0.05)$. There was however, a correlation between the type of skin opening and the occurrence of infection, $\mathrm{p}=0.01(\mathrm{p}<0.05)$.

There were 5 cases of infection among the 25 fractures operated by junior surgeons and 6 cases out of the 32 patients in the senior surgeon group. We failed to establish a relationship between surgeon experience and the occurrence of infection, $\mathrm{p}=0.0457(<0.05)$.

Ten cases of infection were recorded among the 22 positive preoperative CRP testing and no case of infection was recorded among the 5 normal preoperative CRP testing. An infection was recorded in a patient whose CRP was not performed. No correlation was found between the positive value of the pre-operative CRP and the occurrence of infection.

Seven cases of infection were treated with early revision and appropriate antibiotherapy. The remaining 4 were complicated of osteomyelitis $(n=2)$ and septic non-union $(n=2)$.

Six samples were taken, four were positive and 2 were negative (Table 3 ).

The average time of hospitalization was 22 days with a range of 5 to 200 days. The average time of consolidation was 7 months with a range of 3 months to 36 months

\section{Discussion}

Infection is the obsession of the surgeon in the management of open fractures and there is $10 \%$ frequency of deep infection. Traditional recommendations hold that open fractures in adults require urgent surgical debridement for a number of reasons, including the preservation of soft-tissue viability and vascular status as well as the prevention of infection.

In open leg fractures, intramedullary nailing has found a renewed interest since the development of locked nails without boring [1]-[3]. Its use and indications are well codified. To minimize the risk of infection, intramedullary nailing is no longer a therapeutic option beyond the sixth hour, and in this case, external fixating remains the gold standard. Under the rule of 6 hours, performing an intramedullary nailing after the sixth hour poses a real ethical dilemma [13] [14]. The timing of surgery of open fractures remains a real issue in our context [8] [9] [13]. The average waiting time before surgery in our series was 2 days with a range of 1 to 20 days. In developed countries, the proximity of the quality of care and the rapid evacuation of victims of road traffic accidents mean that almost all patients are treated within 6 hours after an open fracture of the legs [1]-[3].

Delays in surgery are caused by an inadequate health system, coupled with the lack of skilled personnels in most areas, requiring secondary transfers for several hours from such remote areas of the country. Another handicap is the shortage of implant such as external fixators. The financial hardship endured by our people limit their ability to meet the basic cost of operating kits, and this as such, is also an important limiting factor for early surgery. This reality is specific to many developing countries [9] [15] [16].

We recorded 11 cases of infection in our series, which is an overall infection rate of $17.5 \%$. However, studies showed that there is no significant statistical difference between open fractures operated before or after the $6^{\text {th }}$ hour time and the occurrence of infection [14] [17]-[19]. Surgeon's experience plays no role on the occurrence of an infection after nailing. We found a significant statistical correlation between the type of fracture and the 
Table 2. Rate of infection according to time to debridement and type of Open wound.

\begin{tabular}{cccc}
\hline & Debridement and nailing & & \\
\hline Cauchoix and Duparc classification & $\mathbf{6}-\mathbf{2 4} \mathbf{~ H}$ & $>\mathbf{2 4} \mathbf{~ H}$ & Infection \\
\hline Type I & 16 & 18 & 2 \\
Type II & 10 & 19 & 9 \\
Total & 26 & 37 & 11 \\
\hline
\end{tabular}

We failed to establish a relationship between the timing of treatment and the occurrence of infection for both type I and type II open fractures treated during the same time intervals, $p=0.244(>0.05)$. There was however, a correlation between the type of skin opening and the occurrence of infection, $p=0.01(\mathrm{p}<0.05)$.

\begin{tabular}{|cc|} 
Table 3. Different micro-organism associated with infection. & \\
\hline Germes & Rate \\
\hline none & 2 \\
Escherichia coli & 1 \\
Enterobacter cloacae & 1 \\
Pseudomonas aeruinosa & 1 \\
Staphylococcus aureus & 1 \\
Total & 6 \\
\hline
\end{tabular}

occurrence of infection. But there is no significant difference between nailing performed within 6 to 24 hours and those after 24 hours and the occurrence of infection. This has been reported by other studies [3] [14].

Risk factors include the initial degree of soiling, the importance of contusion of soft tissues and fracture comminution. Early surgery remains the gold standard [1] [2] [13] [17] [18]. The importance of a complete and yet tailored debridement could not be further stressed given our working conditions, and should include irrespective of timing, extensive washing with foaming iodine solution, isotonic saline and hydrogen peroxide [6]. Subsequent clinical studies that have been performed during the antibiotic era have indicated that the timing of surgical debridement of open fractures may not play as critical a role in the prevention of acute infection [18]. The most crusial factors are prolonged or appropriate antibiotherapy and early revision [5] [8] [13] [15] [20].

Infection rates varie from one author to the other; Bahebeck [8] and Ikem [13] found 6\%, $11.6 \%$ and 39.3\% respectively. Variation of rates could be explained by timing of surgery, and more imprtantly the regularity of antibiotherapy and working conditions [15] [19]. It is important that patients meet the cost of their antibiotics from admission to healing.

Planning intramedullary nailing beyond the sixth hour poses a real dilema in bilateral leg fractures or floating knee, especially when the tibial or the femoral fracture is closed. The strategy in these cases is to perform nailing of the two fractures during the same operation [21].

Secondary intramedullary nailing could be an alternative in delayed surgery as advocated by Sie Essoh [10]. But this option is a luxury in our health care system where all costs are met by the patient. In most series, staphylococci is responsible for infection in open fractures. In our series, infection was heterogeneous with contamination from Escherichia coli, Enterobacter cloacae and Pseudomonas. The presence of these germs could be explained by sterilization processes of our operating rooms, but also by the conditions of hospitalization and dressings [5].

Currently CRP coupled with the VS is important markers in the diagnosis of infection [22]. Unlike some authors, we have not established a correlation between the positive values of preoperative CRP and the occurrence of infection in the postoperative follow-up [22]. CRP as well as antibiotherapy or swabbing for bacterial and fungal susceptibility testing, however essential, has a cost and perceived by most patients as being too expensive. The lack of statistically significant correlation between the preoperative CRP in our study should be interpreted with caution. Preoperated CRP was only carried out in some patients and the study sample was limited.

Osteomyelitis and nonunion are the major complications of open fractures of the legs [3]. They constitute a therapeutic challenge for the surgeon and patients should expect to longer hospital stay or repeat hospitaliza- 
tions.

\section{Conclusion}

The rule of six hours is difficult to apply in our context. We use intramedullary nailing, but external fixators remains the tool of choice. Our study showed no correlation between the preoperative period and the occurrence of infection. Risk factors include the initial degree of soiling, the importance of contusion of soft tissues and fracture comminution. The most crucial factors are prolonged or appropriate antibiotherapy and early revision. Multicentre studies in hospitals where working conditions are the same as ours are to be encouraged, so to solve the dilemma of nailing open fractures seen way beyond the required time.

\section{References}

[1] Bonneviale, P. (2000) Surgical Indications in the Treatment of Open Leg Fractures. Conférences d'Enseignement de la SOFCOT, 73, 91-104.

[2] Kevin, E.C. and Bruce, H.Z. (2002) Open Fractures: Where Are We Now? Operative Techniques in Orthopeadics, 4, 253-257.

[3] Kamal, B., Sameer, A., Vishal, K., Aditya, K.M., et al. (2011) Operative Management of Type II and Type IIIa Open Tibial Fractures Presenting from 6 - 24 Hours after Injury: An Indian Experience. Current Orthopaedic Practice, 22, 262-266. http://dx.doi.org/10.1097/BCO.0b013e31821374ba

[4] Bhandari, M., Guyatt, G.H., Swiontkowski, M.F. and Schemitsch, E.H. (2001) Treatment of Open Fractures of the Shaft of the Tibia. The Journal of Bone \& Joint Surgery, 83-B, 62-68. http://dx.doi.org/10.1302/0301-620X.83B1.10986

[5] Gagey, O., Doyon, F., Dellamonica, P., Carsenti-Etesse, H., et al. (1999) Infection Prophylaxy in Open Tibial Fractures. Pefloxacine versus Cefazolin-Oxacilline. A 616 Cases Randomised Study. Revue Chirurgie Orthopédique, 85, 328-336.

[6] Friedrich, P.L. (1898) Die Aseptische Versorgung Frischer Wunden. Archiv für Klinische Chirurgie, 57, $288-310$.

[7] Robson, M.C., Duke, W.F and Krizek, T.J. (1973) Rapid Bacterial Screening in the Treatment of Civilian Wounds. Journal of Surgical Research, 14, 426-430. http://dx.doi.org/10.1016/0022-4804(73)90049-8

[8] Bahebeckh, J., Balep, J., Arabo, S. and Ngo Yamben, M.AC. (2012) Intramedular Nailing of Type I \& II Open Fracture Seen after $6^{\text {th }}$ Hour: Methods \& Results, a Report of 33 Cases. Orthopaedica Emergencia Africa, 1, 20-23.

[9] Souna, B.S., Ganda, S., Amadou, S. and Abdoulaye, A. (2008) The Treatment of Tibia Open Fractures by Hoffmann External Fixation in Niamey. About 50 Cases. Mali Médical, 23, 11-15.

[10] Sie Essoh, J.B., Bamba, I., Agoh, S., Kacou, A.D. and Dje Bi Dje, V. (2001) Secondary Nailing of Open Fracture of the Tibia. Preliminary Study of 14 Cases. Revue Africaine de Chirurgie, 4, 140-143.

[11] Cauchoix, J., Duparc, J. and Boulez, B. (1957) Treatment of Open Legs Fractures. Mémoires de l'Académie de Chirurgie, 83, 811-822.

[12] Muller, M.E., Nazarian, S., Koch, P. and Schatzker, J. (1990) The Comprehensive Classification of Fractures of Long Bones/AO Classification of Fractures. Springer-Verlag, Berlin, Heidelberg. http://dx.doi.org/10.1007/978-3-642-61261-9

[13] Ikem, I.C., Oginni, L.M. and Ogunlusi, J.D. (2006) Determinants of Management Outcome in Open Tibia Fractures in Ile-Ife. Nigerian Journal of Surgical Research, 8, 81-83.

[14] Jai, S., Ian, H. and Mohamed, M. (2007) The Effect of Time to Theatre on Infection Rate for Open Tibia Fractures. Anz Journal of Surgery, 77, 886-888. http://dx.doi.org/10.1111/j.1445-2197.2007.04266.x

[15] Omololu, B., Ogunlade, S.O., Adekolujo, O.S., Falebita, O.A. and Onasanya, O.M. (2005) Open Tibial Fractures in an African Teaching Hospital: An Initial Study. European Journal of Scientific Research, 11, 230-235.

[16] Twagirayezu, E., Dushimiyimana, J.M.V. and Bonane, A. (2008) Open Fractures I Rwanda: The Kigali Experience. East and central African Journal of Surgery, 13, 77-84.

[17] Melvin, J.S., Domlersski, D.G., Torbert, J.T., Kovach, S.J., et al. (2010) Open Tibial Shaft Fracture: I. Evaluation and Initial Wound Management. Journal of the American Academy of Orthopaedic Surgeons, 18, 10-19. http://dx.doi.org/10.5435/00124635-201001000-00003

[18] Harley, B.J., Beaupre, L.A., Jones, C.A., Dulai, S.K. and Weber, D.W. (2002) The Effect of Time to Definitive Treatment on the Rate of Nonunion and Infection in Open Fractures. Journal of Orthopaedic Trauma, 16, 484-490. http://dx.doi.org/10.1097/00005131-200208000-00006 
[19] Kamat, A.S. (2011) Infection Rates in Open Fractures of the Tibia: Is the 6-Hour Rule Fact or Fiction? Advances in Orthopedics, 27, 1-4. http://dx.doi.org/10.4061/2011/943495

[20] Pollak, N., Jones, A.L., Castillo, R.C., Bosse, M.J. and MacKenzie, E.J. (2010) The Relationship between Time to Surgical Debridement and Incidence of Infection after Open High Energy. The Journal of Bone \& Joint Surgery, 92-A, 7-15. http://dx.doi.org/10.2106/JBJS.H.00984

[21] Sie Essoh, J.B., Traore, A., Bamba, .I, Kacou, A.D., et al. (2001) Bilateral Tibial Shaft Fractures: Diagnosis and Treatment Protocol. Revue Africaine de Chirurgie, 1, 72-74.

[22] Ho, A. and Mcharo, C.N. (2010) C-Reactive Protein Response in Open Fractures of the Tibia. South Africa Orthopaedic Journal, 9, 24-29.

\section{Submit or recommend next manuscript to SCIRP and we will provide best service for you:}

Accepting pre-submission inquiries through Email, Facebook, LinkedIn, Twitter, etc.

A wide selection of journals (inclusive of 9 subjects, more than 200 journals)

Providing 24-hour high-quality service

User-friendly online submission system

Fair and swift peer-review system

Efficient typesetting and proofreading procedure

Display of the result of downloads and visits, as well as the number of cited articles

Maximum dissemination of your research work

Submit your manuscript at: http://papersubmission.scirp.org/ 